\title{
Nanopolystyrene translocation and fetal deposition after acute lung exposure during late-stage pregnancy
}

Sara B. Fournier ${ }^{1}$, Jeanine N. D'Errico ${ }^{2}$, Derek S. Adler ${ }^{3}$, Stamatina Kollontzi ${ }^{4}$, Michael J. Goedken ${ }^{5}$, Laura Fabris ${ }^{4}$, Edward J. Yurkow ${ }^{3}$ and Phoebe A. Stapleton ${ }^{1,2^{*}}$ (i)

\begin{abstract}
Background: Plastic is everywhere. It is used in food packaging, storage containers, electronics, furniture, clothing, and common single-use disposable items. Microplastic and nanoplastic particulates are formed from bulk fragmentation and disintegration of plastic pollution. Plastic particulates have recently been detected in indoor air and remote atmospheric fallout. Due to their small size, microplastic and nanoplastic particulate in the atmosphere can be inhaled and may pose a risk for human health, specifically in susceptible populations. When inhaled, nanosized particles have been shown to translocate across pulmonary cell barriers to secondary organs, including the placenta. However, the potential for maternal-to-fetal translocation of nanosized-plastic particles and the impact of nanoplastic deposition or accumulation on fetal health remain unknown. In this study we investigated whether nanopolystyrene particles can cross the placental barrier and deposit in fetal tissues after maternal pulmonary exposure.
\end{abstract}

Results: Pregnant Sprague Dawley rats were exposed to $20 \mathrm{~nm}$ rhodamine-labeled nanopolystyrene beads $\left(2.64 \times 10^{14}\right.$ particles) via intratracheal instillation on gestational day (GD) 19. Twenty-four hours later on GD 20, maternal and fetal tissues were evaluated using fluorescent optical imaging. Fetal tissues were fixed for particle visualization with hyperspectral microscopy. Using isolated placental perfusion, a known concentration of nanopolystyrene was injected into the uterine artery. Maternal and fetal effluents were collected for $180 \mathrm{~min}$ and assessed for polystyrene particle concentration. Twenty-four hours after maternal exposure, fetal and placental weights were significantly lower (7 and $8 \%$, respectively) compared with controls. Nanopolystyrene particles were detected in the maternal lung, heart, and spleen. Polystyrene nanoparticles were also observed in the placenta, fetal liver, lungs, heart, kidney, and brain suggesting maternal lung-to-fetal tissue nanoparticle translocation in late stage pregnancy.

Conclusion: These studies confirm that maternal pulmonary exposure to nanopolystyrene results in the translocation of plastic particles to placental and fetal tissues and renders the fetoplacental unit vulnerable to adverse effects. These data are vital to the understanding of plastic particulate toxicology and the developmental origins of health and disease.

Keywords: Nanoplastics, Translocation, Pregnancy, Maternal, Fetal, Polystyrene, Perfusion

\footnotetext{
* Correspondence: stapleton@eohsi.rutgers.edu

${ }^{1}$ Environmental and Occupational Health Sciences Institute, Rutgers

University, 170 Frelinghuysen Rd, Piscataway, NJ 08854, USA

${ }^{2}$ Department of Pharmacology and Toxicology, Ernest Mario School of

Pharmacy, Rutgers University, 160 Frelinghuysen Rd, Piscataway, NJ 08854,

USA

Full list of author information is available at the end of the article
}

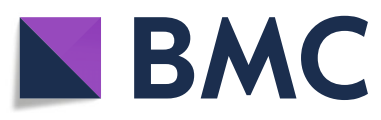

(c) The Author(s). 2020 Open Access This article is licensed under a Creative Commons Attribution 4.0 International License, which permits use, sharing, adaptation, distribution and reproduction in any medium or format, as long as you give appropriate credit to the original author(s) and the source, provide a link to the Creative Commons licence, and indicate if changes were made. The images or other third party material in this article are included in the article's Creative Commons licence, unless indicated otherwise in a credit line to the material. If material is not included in the article's Creative Commons licence and your intended use is not permitted by statutory regulation or exceeds the permitted use, you will need to obtain permission directly from the copyright holder. To view a copy of this licence, visit http://creativecommons.org/licenses/by/4.0/. The Creative Commons Public Domain Dedication waiver (http://creativecommons.org/publicdomain/zero/1.0/) applies to the data made available in this article, unless otherwise stated in a credit line to the data. 


\section{Background}

Plastics are ubiquitous in modern society, used worldwide in a variety of applications ranging from manufacturing, packaging materials, personal products, and medical devices. Growing production and postconsumer plastic waste disposal contribute to the accumulation of plastic in landfills, waterways, and oceans [1]. In the natural environment, material fragmentation of bulk plastic waste by a combination of physical, chemical, and biological processes produces smaller particles referred to as microplastics $(<5 \mathrm{~mm}$ in a single dimension [2] $)$ and nanoplastics $(<100 \mathrm{~nm}$ in a single dimension). Recent literature identified microplastics in atmospheric fallout $[3,4]$ and as a significant component of indoor air pollution [3]. These findings have raised concerns for potential adverse health effects of human nanoplastic particle inhalation [5]. In an occupational setting the potential for unintentional exposure to aerosolized micro- and nanoplastics is a critical issue. According to the United States Department of Labor Occupational Safety and Health Administration (OSHA) Regulation 1910.1000 Table Z pertaining to toxic and hazardous air contaminants, there are presently no occupational exposure limits for aerosolized micro- or nanosized plastic particles, likely these particles are grouped into "particles not otherwise regulated" and/or "inert or nuisance dust" [6]. Current data on exposure to microand nanoplastics in a consumer or occupational context are very limited as the quantification of emissions in a background of ambient air particles cannot be accurately measured with existing technology [7] but may be estimated based on fragmentation of microplastics in the environment. A recent meta-analysis demonstrated that adult women are exposed to an average of 258 microplastic particles per day, of which inhalation accounts for 132 microplastic particles [8].

Unfortunately, very little is understood pertaining to the toxicology of nanoplastic particles; however, the physiological concerns of other engineered nanoparticles in a similar size range have been identified. Compared with like particles of a larger size, nanoparticles have the propensity to access deeper regions of the lung and cross biological barriers [9]. Recently, studies in mammalian models have identified maternal-to-offspring translocation of silver nanoparticles after pulmonary exposure, raising concerns for the risk of adverse health effects in dams and embryos/fetuses during pregnancy [10]. We have reported particle translocation of multi-walled carbon nanotubes (MWCNT) to the heart, kidneys, and other systemic tissues after inhalation of MWCNT aerosols in young adult male rats [11]. These studies demonstrate the probability of nanosized particles to translocate across pulmonary cell barriers to secondary organs, including the placenta. Furthermore, gold has been detected in the blood and urine of healthy human volunteers following acute inhalation of engineered gold nanoparticles [12]; also titanium was identified in the spleen and liver of young adult (12-13 weeks) and aged (19 months) rats exposed to a $\mathrm{TiO}_{2}$ nanostructured aerosol [13]. Although these studies identify the ionic dissociation and not the metallic particle, these outcomes may have relevance to the release of chemicals adsorbed to the surface of plastic particles in a biological environment [14].

While investigations of the impact of micro- and nanoplastic pollution in terrestrial ecosystems are limited, numerous studies have documented the effects of micro- and nanoplastics in the aquatic environment [5, 15, 16]. Mattsson et al. reported trophic transfer from prey to predator within a laboratory-simulated food chain where $53 \mathrm{~nm}$ polystyrene particles transferred from algae to the zooplankton Daphnia magna, and then to a freshwater fish [17]. Polystyrene nanoparticles (i.e., $42 \mathrm{~nm}$ ) were identified in the yolk sac, gastrointestinal tract, liver, and pancreas of larvae and F1 embryos after maternal ingestion, providing evidence of maternaloffspring transfer in a non-placental vertebrate exposure model [18]. Cellular uptake of polystyrene nanoparticles $(25 \mathrm{~nm}$ and $70 \mathrm{~nm})$ has been reported in human alveolar epithelial A549 cells [19]. Nanopolystyrene exposure reduced cell viability, induced cell cycle $S$ phase arrest, and up-regulation of pro-inflammatory cytokines and proapoptotic proteins [19]. Importantly, exposure duration, particle diameter, and concentration were key determinants of the toxicological effects of polystyrene nanoparticle exposure on alveolar epithelial cells [19].

While information about the risk of airborne microand nanoplastic particles to human health is limited, using an ex vivo human placental perfusion model, Wick et al. confirmed size-dependent maternal-to-fetal placental translocation of fluorescent polystyrene particles (50 $\mathrm{nm}, 80 \mathrm{~nm}$, and $240 \mathrm{~nm}$ ) [20]. Furthermore, Grafmueller et al. examined the bidirectional transfer of polystyrene particles using the ex vivo human placental perfusion model and observed placental translocation and particle accumulation in the syncytiotrophoblast of the placental tissue [21]. Investigators reported that nanoparticle translocation across the human placenta was dependent on particle physio-chemical characteristics and functionalization and was likely to involve an active, energy-dependent transport pathway [21]. While it is understood that nanoplastic particles are likely to reach the fetal tissues after maternal inhalation, the impact of maternal lung exposure to nanoplastic particles on fetal development and particle deposition within the fetus remains unclear [10, 21]. In this study, we examine the translocation and deposition/accumulation of nanopolystyrene particles in maternal and fetal tissues after a 
maternal pulmonary exposure in rats during late gestation. Furthermore, we assess the impact of nanopolystyrene particles on fluid flow in real-time across the live placenta using an isolated ex vivo utero-placental perfusion system.

\section{Materials and methods Polystyrene Nanobeads}

Stock solutions of commercially available $20 \mathrm{~nm}$ rhodamine-labeled polystyrene beads $\left(8.8 \times 10^{14}\right.$ particles/mL, PS20-RB-2; NanoCS, New York, NY) were suspended at a concentration of $1 \%$ in distilled water and $0.01 \%$ surfactant and sonicated for $5 \mathrm{~min}$ on ice prior to measurement. The size of the nanoparticles was measured with Non-Invasive Backscatter optics (NIBS) using a $4 \mathrm{~mW}, 633 \mathrm{~nm}$ laser. The ENM $\zeta$-potential was also measured via Zetasizer Nano ZS. Particle size was independently verified by collaborative research partners in the Department of Materials Science and Engineering. An in-house assessment of the rhodamine-labeled polystyrene beads revealed an average particle agglomerate size of $21.86 \mathrm{~nm} \pm 0.026$ and a $\zeta$-potential of $-0.0874 \pm 0.195$.

\section{Animals}

Time-pregnant Sprague Dawley rats $(n=21)$ were ordered from Charles River Laboratories (Kingston, NY). Animals were delivered on gestational day (GD) 15 and allowed to acclimate within an AAALAC accredited vivarium at Rutgers University for at least $96 \mathrm{~h}$. Animals were single housed in standard caging and had access to food and water ad libitum. Rats were randomly assigned to a treatment group upon arrival. All procedures were approved by the Institutional Animal Care and Use Committee of Rutgers University.

\section{Exposure}

Rhodamine-labeled nanopolystyrene particles were prepared by vortexing $300 \mu \mathrm{l}$ of manufacturer's suspension for $2 \mathrm{~min}$, followed by ultra-sonication on ice, for $5 \mathrm{~min}$ as previously described [22, 23]. On GD 19 rats were anesthetized with isoflurane gas (5.0\% induction). Animals were placed supine on an angled board by suspending the upper incisor teeth on an incisor loop at a $45^{\circ}$ angle. The tongue was retracted using forceps and a cotton-tipped applicator. Using a veterinary operating otoscope fitted with a speculum, the epiglottis was visualized, and a 20 gauge, 4-in. stainless steel ball-tipped oral gavage needle was inserted via the mouth to the trachea. The rats received intratracheal instillation of $300 \mu \mathrm{L}\left(2.64 \times 10^{14}\right.$ particles $)$ of nanopolystyrene suspension as described above or vehicle $(0.9 \% \mathrm{NaCl})$. Rats were monitored after instillation and anesthesia until they regained consciousness and normal physiological activity (e.g., walking, eating, drinking, grooming, and resting).

\section{Fluorescent Optical Imaging}

Twenty-four hours after exposure on GD 20, dams were fully anesthetized with 3-5\% isoflurane in oxygen and the depilatory agent Nair ${ }^{\text {rm }}$ was applied to the abdominal region to remove hair prior to imaging. The animal was transferred into the Bruker In-Vivo Multispectral (MS) FX PRO Imager (Bruker, Billerica, MA, USA) imaging chamber with nose cone attached to the manifold and placed in the prone position. The MSFX Pro Bruker detects bioluminescence, fluorescence, radio isotope, and X-ray.

A brightfield image was taken to confirm positioning and provide a snapshot/photo of the scan. The primary scans consisted of an excitation of $480 \mathrm{~nm}$ with an emission of $535 \mathrm{~nm}$ for a 1-min exposure. Later scans consisted of an excitation of $550 \mathrm{~nm}$ with an emission of $600 \mathrm{~nm}$. For these scans, the detectable light refracting off the contrast was recorded. The final scan in this series was an X-ray of the sample that assisted with coregistration of the signal with organ tissues. Following live imaging, animals were sacrificed by removal of the heart according to the Rutgers IACUC approval. Maternal tissues, periparturient fetuses, and fetal tissues were harvested and placed on a polycarbonate tray. After tissue scans were complete, the regions of interest were measured using Bruker MSFX PRO Image software.

Hyperspectral-enhanced darkfield microscopy: Formalin fixed fetal tissues were processed, embedded in paraffin, and sectioned to $4 \mu \mathrm{m}$. Slides were visualized via transmitted darkfield hyperspectral images and data captured using CytoViva optics at 60x magnification with oil objective. Dual Mode Fluorescence (DMF) and full fluorescence images were captured with Texas Red excitation filter and triple pass emission filter for further particle confirmation. Data was processed using ENVI 4.8 (CytoViva, Inc., Auburn, AL).

\section{Placental Isolation and Perfusion}

A separate cohort of naïve gravid rats $(n=14)$ were anesthetized with isoflurane $(5 \%$ induction and $3 \%$ maintenance) on GD 20. The right uterine horn was isolated, removed, and placed into a dish of cold $\left(4^{\circ} \mathrm{C}\right)$ physiological salt solution (PSS). Briefly, the uterine horn was dissected, placental unit was identified, amniotic sac opened, fetus removed, and umbilical vessels were ligated and unraveled as previously described [24, 25]. The placental unit was removed and placed into a modified isolated vessel chamber (Living Systems Instrumentation, Burlington, VT) filled with warmed $\left(37^{\circ} \mathrm{C}\right)$, oxygenated $\left(21 \% \mathrm{O}_{2}-5 \% \mathrm{CO}_{2}-74 \% \mathrm{~N}_{2}\right)$, circulating PSS. The placental vasculature (uterine artery and umbilical 
artery and vein) were secured to glass pipettes or 26 gauge, 4-in. stainless steel blunt needles, respectively. The uterine artery was perfused with a peristaltic pump at $80 \mathrm{mmHg}$ and the umbilical artery was perfused at 50 mmHg. Rhodamine-labeled nanopolystyrene particles were prepared as described above by vortexing $1 \mathrm{~mL}$ of manufacturer's suspension for $2 \mathrm{~min}$, followed by ultrasonication on ice, for $5 \mathrm{~min}$ as previously described [22, 23]. After a 30-min equilibration and 10-min baseline, a bolus of $900 \mu \mathrm{L}\left(7.92 \times 10^{14}\right.$ particles $\left./ \mathrm{mL}\right)$ of nanopolystyrene particles were slowly injected into the uterine artery. Effluents were collected and weighed from the distal uterine artery and umbilical vein cannula at 10min intervals for a total of $180 \mathrm{~min}$. The remaining fluid within the stainless-steel needle cannulating the umbilical vein was collected.

\section{Quantification of Nanopolystyrene particles}

Twenty five $\mu \mathrm{L}$ of effluent from each sampling time point was pipetted in duplicate on a 96-well clear bottom plate. The positive control was identified as $25 \mu \mathrm{L}$ of stock solution of $20 \mathrm{~nm}$ rhodamine-labeled polystyrene beads and the negative control as PSS only. All samples were diluted by adding $100 \mu \mathrm{L}$ of PSS into each well. Fluorescence was measured by a spectrophotometer at $546 / 575 \mathrm{~nm}$ (excitation/emission) using a SpectraMax M3 fluorescent microplate reader (Molecular Devices, Sunnyvale, CA). Data were collected using SoftMax Pro 6.3 software.

To confirm that the rhodamine tag remained attached to the polystyrene beads throughout the perfusion, maternal and fetal effluents were pooled together for 4 representative experiments. The samples were centrifuged at $100,000 \times \mathrm{g}$ for $1 \mathrm{~h}$ in an ultracentrifuge (Beckman Coulter Max-XP tabletop Ultracentrifuge) to pellet polystyrene ENM. Twenty five $\mu \mathrm{L}$ of supernatant was removed from each sample and placed in a 96-well clear bottom plate and read at 546/575 nm (excitation/ emission) using a SpectraMax M3 fluorescent microplate reader (Molecular Devices, Sunnyvale, CA). Data were collected using SoftMax Pro 6.3 software.

\section{Histology}

Representative placentas from the perfusion experiments were fixed in $10 \%$ neutral buffered formalin, processed and sectioned to $4 \mu \mathrm{m}$. Hematoxylin and eosin (H\&E) stained slides were assessed by an ACVP board-certified veterinary pathologist.

\section{Statistics}

Outliers were identified using Grubb's test and removed from the data presented in Table 1. All other results are presented in their entirety. All data were analyzed by Student's t-test using MS Excel. Statistical significance was set to $p<0.05$ and is indicated with an asterisk $(*)$. Trends were identified as $p<0.10$ and are indicated with a (T). ANCOVA analyses were also run using Sigma Plot 13.0 to assess if pup and placental weights were impacted by litter size.

\section{Results \\ Exposure Dosimetry: extrapolation to real-world conditions}

The concentration of microplastic particles has been measured in both atmospheric and indoor air [3, 4, 8]. Unfortunately, nanosized particles have not been directly measured in real-world conditions; because of their small size, they generally escape traditional containment and filtering systems. Therefore, to extrapolate nanopolystyrene particle dosage, we considered an $1 \mathrm{~mm}^{3}$ atmospheric microparticle and mathematically converted this to nanosized particles representative of our spherical $20 \mathrm{~nm}$ polystyrene beads. Consequently, a single microparticle represents $2.39 \times$ $10^{14}$ nanopolystyrene particles (Fig. 1a). Cox et al. reported that the average women inhales 132 microplastic particles per day [8]. Given that maternal minute ventilation, or the volume of gas inhaled, increases by up to $48 \%$ during pregnancy while the respiration rate remains unchanged [26], it is likely that daily total exposure is closer to the upper bound of 279 microplastics identified in the study [8]. These data suggest that the average pregnant woman could be exposed to $6.67 \times 10^{16}$ nanoplastic particles per day (Fig. 1b). When the surface area of the lung between human $\left(62.7 \mathrm{~m}^{2}\right)$ and our laboratory rat $\left(0.409 \mathrm{~m}^{2}\right)$ model [27] is considered, the appropriate experimental exposure amounts to $4.34 \times 10^{14}$ nanoplastic particles (Fig. 1c). This value is much greater than the exposure dose of $2.64 \times 10^{14}$ nanoplastic particles and therefore, the exposure dose used in this study is within real-world considerations.

\section{Fluorescent optical imaging}

Primary whole animal scan yielded null results as the skin was too dense to visualize any fluorescence (data not shown). Graphical representations of optical intensities are represented for maternal tissues in Fig. 2a and fetal tissues in Fig. 2b. These data indicate significant nanopolystyrene deposition in the maternal lung, heart, spleen, compared to controls and a trend toward significance in the gravid uterus. Deposition of polystyrene was elevated in all exposed fetal tissues that were evaluated. Images obtained from secondary scans of fetal tissues revealed significantly elevated levels of polystyrene in GD 20 fetuses, fetal abdomens, and isolated livers compared with controls. There was an elevated trend in the fetus and placenta 
Table 1 Effect of maternal nanopolystyrene pulmonary exposure on litter characteristics

\begin{tabular}{|c|c|c|c|c|c|c|c|}
\hline Treatment & $n$ & $\begin{array}{l}\text { Maternal Weight } \\
\text { (g) }\end{array}$ & $\begin{array}{l}\text { Number of Fetuses per } \\
\text { Litter }\end{array}$ & $\begin{array}{l}\text { Fetal Weight } \\
\text { (g) }\end{array}$ & $\begin{array}{l}\text { Placental Weight } \\
\text { (g) }\end{array}$ & $\begin{array}{l}\text { Placental } \\
\text { Efficiency }\end{array}$ & $\begin{array}{l}\text { Number of Resorption } \\
\text { Sites }\end{array}$ \\
\hline Saline & 14 & $358 \pm 12$ & $13.1 \pm 0.4$ & $2.71 \pm 0.05$ & $0.48 \pm 0.01$ & $5.57 \pm 0.26$ & $0.42 \pm 0.14$ \\
\hline PS & 11 & $382 \pm 21$ & $12.6 \pm 0.6$ & $* 2.51 \pm 0.06$ & ${ }^{*} 0.43 \pm 0.01$ & $5.79 \pm 0.22$ & ${ }^{*} 1.13 \pm 0.30$ \\
\hline
\end{tabular}

Values are shown as mean \pm SEM

$n$ number of dams. Statistics were analyzed with a one-way analysis of variance $\left({ }^{*} p \leq 0.05\right)$

in its entirety within the amniotic sac, isolated placenta, and isolated fetal hearts. These studies indicate nanopolystyrene particle translocation from the maternal lungs to systemic tissues, including the fetus and fetal organs.

\section{Hyperspectral Darkfield microscopy}

Enhanced darkfield imaging of fetal tissue sections readily demonstrated polystyrene nanoparticle deposition in Fig. 3. Polystyrene nanoparticles were visualized in the fetal liver, lung, kidney, heart, and brain. In
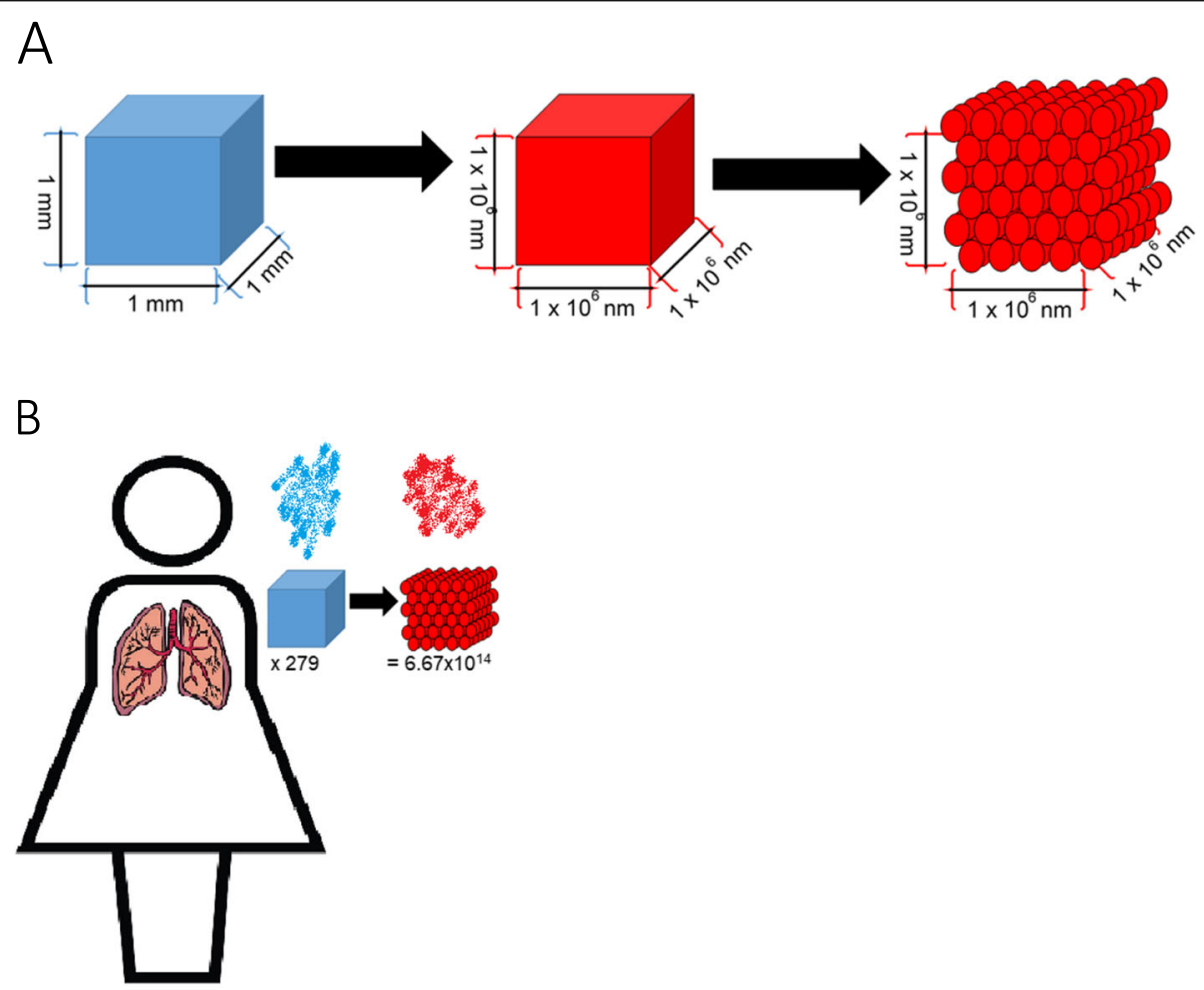

C

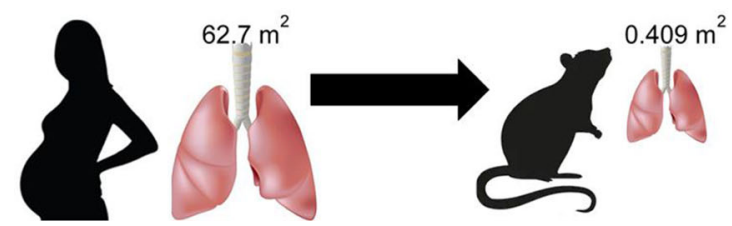

$6.67 \times 10^{14}$ nanoparticles

$4.34 \times 10^{14}$ nanoparticles

Fig. 1 Schematic of nanoplastic exposure and dosimetry. a We utilized a $1 \mathrm{~mm}^{2}$ microparticle as a representative microplastic (blue). The extrapolation of this microplastic microparticle to a nanoparticle is $1 \times 10^{6}$. Our representative nanopolystyrene nanobeads are spherical and 21 $\mathrm{nm}$ in diameter (red). Therefore, there would be $2.39 \times 10^{14}$ nanopolystyrene beads in a single plastic microparticle. b Cox et al. identified that women inhale an average of 132 microplastics. The upper bound of this measurement ( 279 microplastics), is more representative of exposure for pregnant women. The calculated dosage is $6.67 \times 10^{16}$ nanopolystyrene beads. c The surface area of the Sprague Dawley rat lung is significantly smaller $\left(0.409 \mathrm{~m}^{2}\right)$ compared with the human lung $\left(62.7 \mathrm{~m}^{2}\right)$. The calculated dose for a laboratory rat is $4.34 \times 10^{14}$. The exposure dose used in these studies was $2.64 \times 10^{14}$ nanopolystyrene beads 

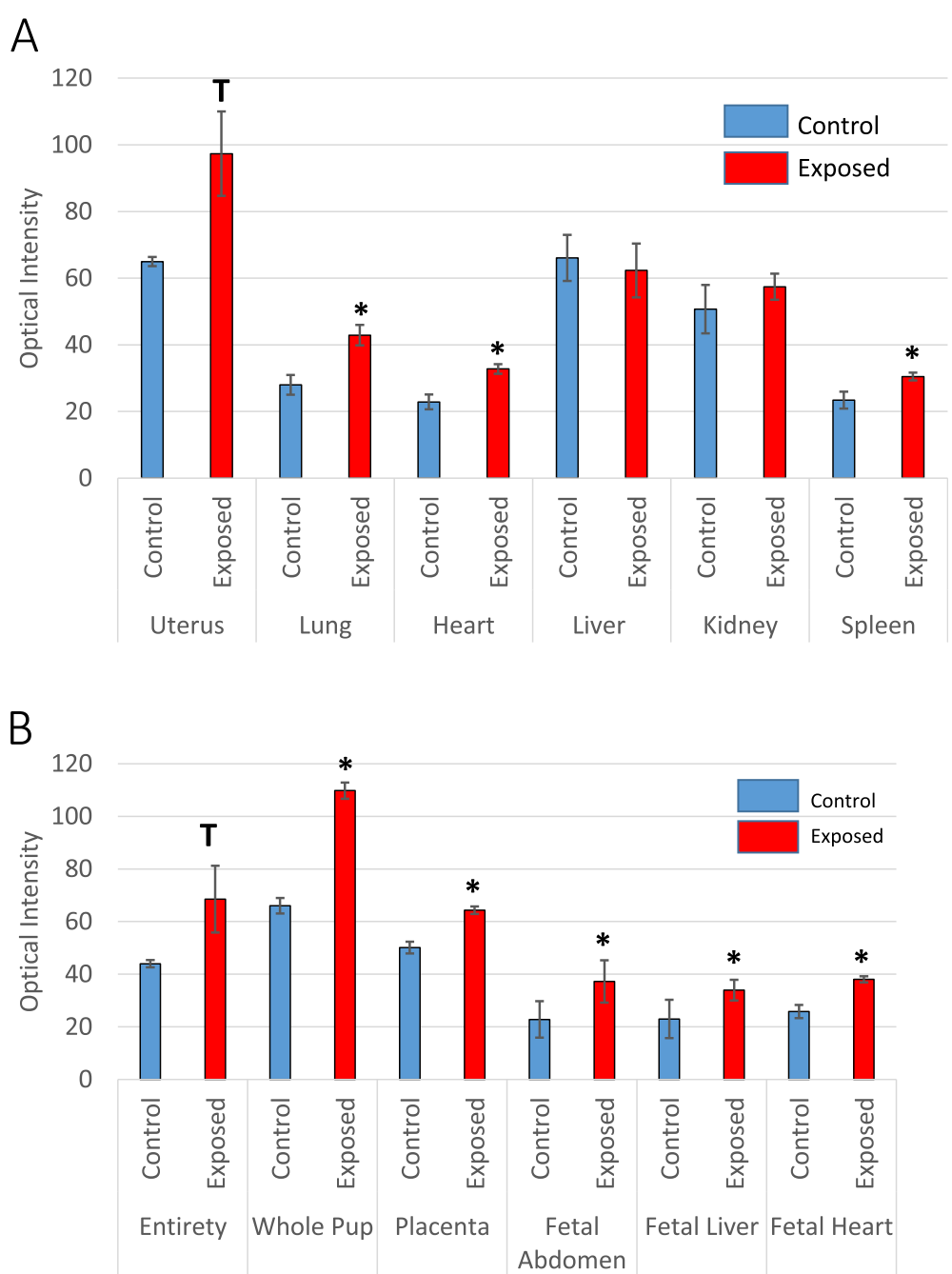

Fig. 2 Optical images of maternal and fetal tissues. Graphical representation of the optical intensities between a maternal and $\mathbf{b}$ fetal control and exposed tissues. $n=6-8$ pregnant rats. Values are shown as mean \pm SEM. Statistics were analyzed with a Student's t-test. $\left({ }^{*} p \leq 0.05 ; T \leq 0.10\right)$

representative images, these particles appear as white dots/spots. These studies further demonstrate nanoplastic particle deposition within fetal tissues.

\section{Placental perfusion}

Polystyrene nanoparticle transfer through the maternal vasculature from the proximal to the distal uterine artery was confirmed within $10 \mathrm{~min}$ of bolus infusion (Fig. 4a). Nanoparticle transfer across the maternal uterine artery peaked at $20 \mathrm{~min}$, remained significantly above baseline for $70 \mathrm{~min}$, and elevated for $100 \mathrm{~min}$. Effluent fluorescence returned to baseline levels after $100 \mathrm{~min}$. Moreover, elevated concentrations of polystyrene nanoparticles were detected in umbilical effluent within 90 min of uterine artery bolus infusion (Fig. 4b). Concentration of the nanoparticles in the umbilical effluent were significantly high after $150 \mathrm{~min}$ through $180 \mathrm{~min}$ after infusion and significant concentrations remained in the umbilical cannula after 180 min of perfusion. There were no significant differences in fluid flow through the umbilical vein between saline perfused placenta (control) and those exposed to nanopolystyrene after the 180-min perfusion (Fig. 4c). Placentae were evaluated after perfusion where no histopathological alterations were identified.

\section{Litter characteristics}

Maternal and fetal parameters including maternal weight, litter size, fetal weight, placental weight, placental efficiency, and total number of sites of resorption are reported in Table 1. In treated dams, fetal and placenta weights were significantly lower in the exposed group compared with control. ANCOVA analyses confirmed that these results were not the product of litter size variation. Number of resorption sites in the exposed group was also significantly greater compared with control. 

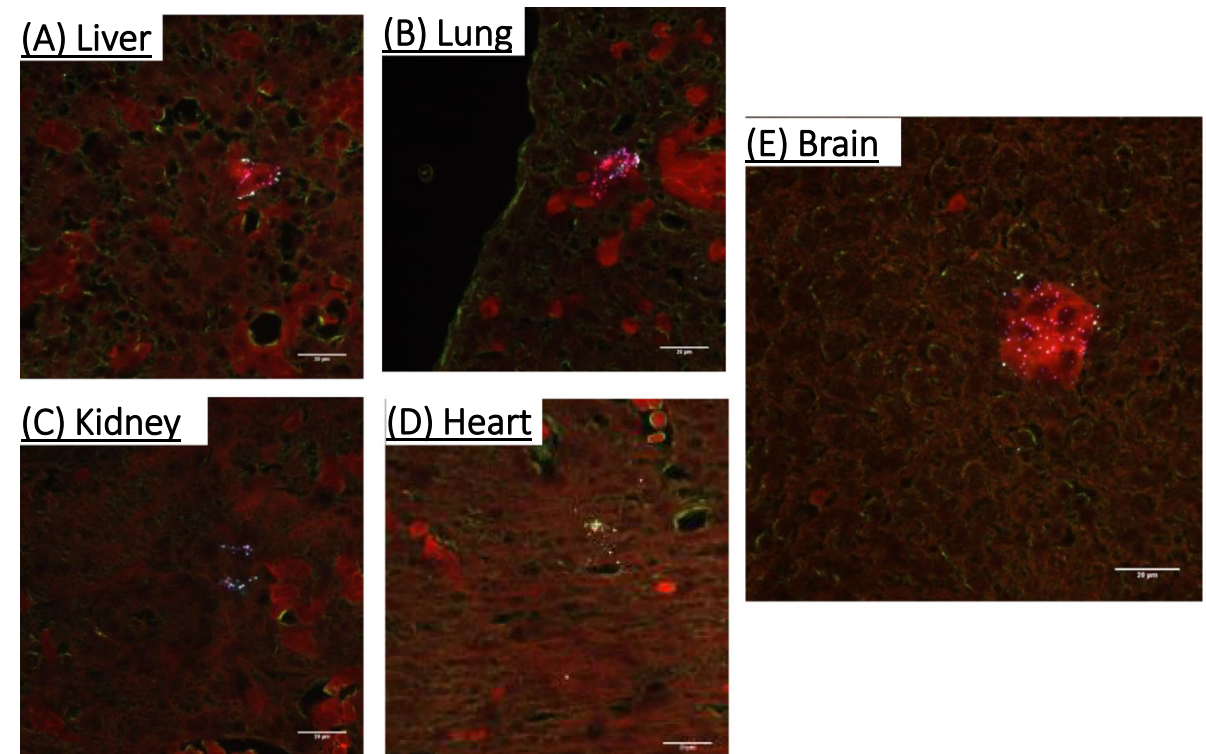

Fig. 3 Identification and visualization of nanopolystyrene particle deposition within the fetal tissues placenta after material pulmonary exposure using enhanced hyperspectral microscopy (CytoViva, Inc.). These tissues include fetal a liver, $\mathbf{b}$ lung, $\mathbf{c}$ kidney, $\mathbf{d}$ heart, and e brain. $n=3$ fetuses from 3 different pregnant rats. Polystyrene nanoparticles are identified as white specs within the images

There were fewer fetuses in dams treated with nanopolystyrene particles, however, this difference did not reach significance in our cohort.

\section{Discussion}

In this study we identified the translocation of nanopolystyrene particles from the maternal lungs, across the placenta, into fetal tissues. Elevated fluorescence from our rhodamine-labeled particles was measured in the maternal lung, heart, spleen, and uterus and fetal placenta, liver, and heart. Nanopolystyrene particles were observed in the fetal liver, lung, kidney, heart, and brain in late-stage pregnancy using dark-field microscopy. Furthermore, using an ex vivo placental perfusion system, we observed the transfer of nanopolystyrene particles from the maternal uterine circulation, across the placenta to the fetal circulation. As is pertains to fetal health, we observed reduced fetal weight, reduced placental weight, and an increase in reabsorption sites $24 \mathrm{~h}$ after maternal nanopolystyrene particle pulmonary exposure.

In this study, we visualized nanopolystyrene translocation from the maternal lungs to the fetal compartment and deposition in the fetal, liver, heart, kidney, and brain on GD 20, within $24 \mathrm{~h}$ of maternal exposure. Our study represents a snapshot of time during gestation, providing evidence that nanoplastic particles can reach fetal tissues after maternal pulmonary exposure. As it pertains to nanoplastic particle deposition, it remains unclear if the nanopolystyrene particles have been taken up by the fetal cells, remain in the fetal vasculature, migrate to the interstitial space, or are returned to the maternal circulation. It is plausible that these particles would remain in the fetus after birth as the nanoplastic particles passaged across the placental barrier and may be taken up by fetal cells. Endothelial cell exposure to engineered nanomaterials enhances endothelial barrier permeability [28-30], which offers accessibility to the interstitial space between cells within systemic tissues. Reports pertaining to the development and function of the blood brain barrier in a fetus are inconclusive [31, 32]. Therefore, the blood-brain barrier may not yet be fully formed, rendering the fetal brain susceptible to particle sedimentation. We, and others, have identified that maternal exposures to metallic and carbonaceous ENM during gestation can initiate developmental onset of disease within the maturing fetus. In laboratory studies, young and adult offspring have been reported to exhibit coronary dysfunction [33-38], vascular perturbations [38, 39], negative reproductive health outcomes [40-42], and neurological outcomes [43-45] after maternal inhalation of engineered nanomaterials during pregnancy. It is also plausible that these findings represent a snapshot of time, wherein the particles reach the fetal tissues within $24 \mathrm{~h}$ of exposure but are removed from the fetal circulation prior to birth. Therefore, particle deposition during fetal development may impact offspring health after birth and into adulthood.

Furthermore, the uptake and passage of nanosized materials is highly dependent on the physio-chemical properties of the particles including size, functionalization, chemical construct, and surface charge [5]. Cellular 


\section{A}

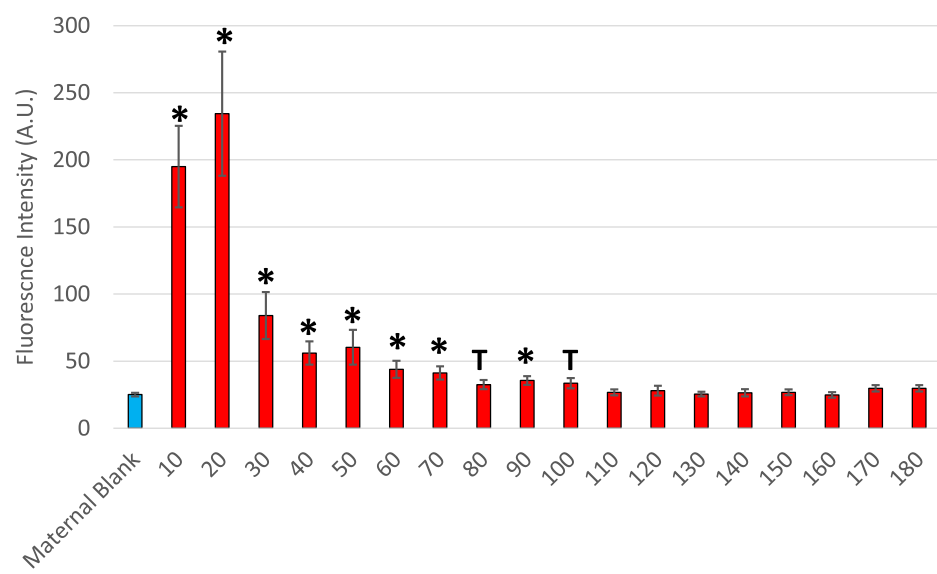

B

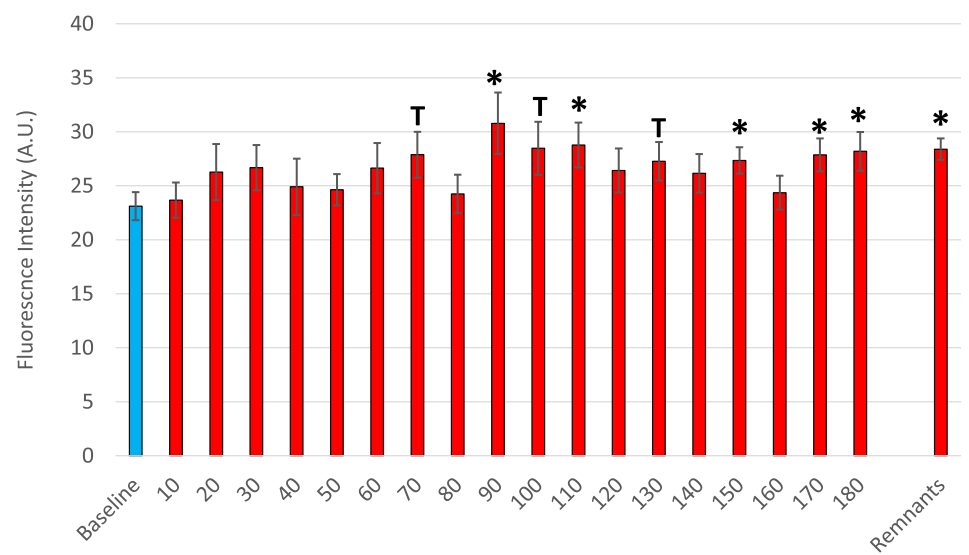

C

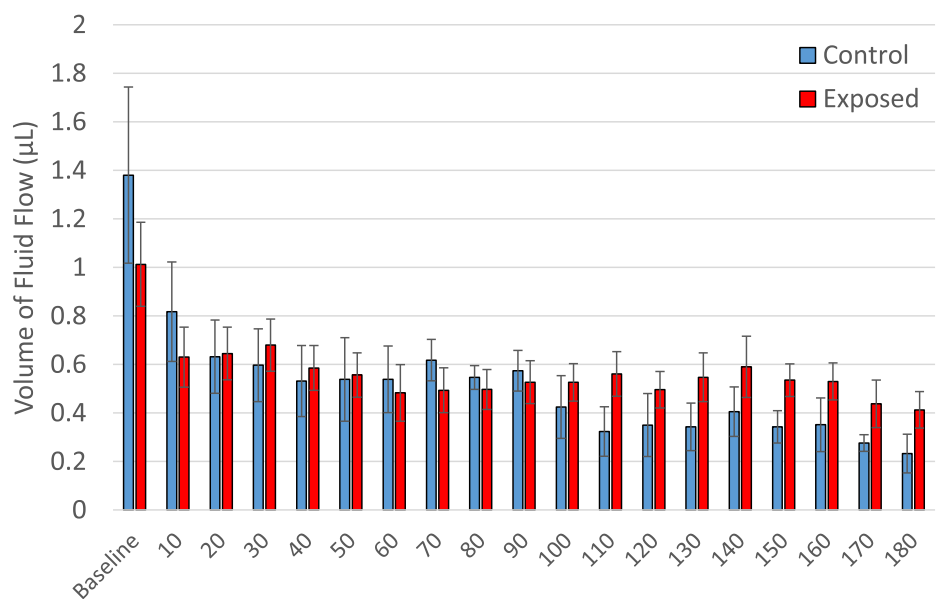

Fig. 4 (See legend on next page.) 
(See figure on previous page.)

Fig. 4 Identification of rhodamine-labeled nanopolystyrene bead translocation based on increased fluorescence through the a distal uterine effluent and $\mathbf{b}$ umbilical vein effluent over time. $n=9-24$. $\mathbf{c}$ Time-course of fluid flow through the umbilical vein between saline (black) and nanopolystyrene (red) infused placenta. $n=6-8$. Values are shown as mean \pm SEM and presented as percent above baseline. Statistics were analyzed with Student's t-test $\left({ }^{*} p \leq 0.05 ; \mathrm{T} \leq 0.10\right)$

uptake and subsequent toxicity of nanoplastic particles is dependent on the unique protein and chemical corona that forms on the surface during contact with biological fluids (e.g. pulmonary surfactant, interstitial fluid, plasma) and environmental chemicals; in the case of plastics these chemicals may be adsorbed and serve and a vehicle for chemical transport [46]. Chemical additives adsorbed to the surface or added to plastics during the polymerization process can leach or be transferred from polystyrene products with normal use. These additives may include carcinogens or endocrine disrupting factors (e.g., vinyl chloride, phthalates) [47, 48]. Fundamental studies of plastics toxicology identify and refer to the potential for chemical leakage from polystyrene products after the addition of hot, cold, or boiling water [49]. Recently, studies identify the propensity for polycyclic aromatic hydrocarbons, specifically pyrene, to dissociate from after aquatic exposure to microplastic particles in a biological environment [14]. Together, these outcomes indicate the possibility of chemical release from particles within an organism. Fetal nanoplastic deposition could lead to life-long localized low-level exposure to these additives or adsorbed chemicals. Future studies are planned to examine chemical release from plastic nanomaterials within a biological environment and to assess the impact of a chronic exposure to nanoplastic particles on fetal growth and development are also required for a comprehensive understanding of the health hazards associated with airborne nanoplastics.

We quantified an elevation in fluorescently labeled nanopolystyrene particles in the umbilical vein within $90 \mathrm{~min}$ of bolus infusion to the uterine artery. These levels were significantly higher within $150 \mathrm{~min}$ of exposure. These results confirm the capacity of $20 \mathrm{~nm}$ nanopolystyrene plastic particles to pass from the maternal to the fetal compartment. Interestingly, while fluid flow from the maternal to fetal compartment decreased after both saline control and nanopolystyrene injection, this was not to significance. This suggests no reduction in blood flow through the placenta within 180-min of particles reaching the uterine artery.

Similarly, Grafmueller et al. demonstrated the placental transfer of fluorescently-labeled nanopolystyrene particles from the maternal to the fetal compartment [20, 21]. Upon further study utilizing the ex vivo human placental perfusion model, the authors identified a bidirectional, size-dependent transfer of nanopolystyrene beads without cytotoxicity [21]. In this study, heightened polystyrene particle transfer from the fetal to the maternal compartment was observed instead of a concentration equilibrium evident of passive transport [21]. Therefore, Grafmueller et al. speculated that nanopolystyrene translocation across the placenta likely involves energydependent uptake, material transfer, and particle efflux as opposed to passive transport [21]. It is recognized that the concentration of particles that translocate from the primary site of exposure to the fetal compartment and tissues is low [50] and that the human placental perfusion methodology is not without limitation [51].

The results of our current study also corroborate data from previous nanotoxicological investigations from our group and others that have shown reduced fetal weight, or restricted fetal growth, after chronic maternal inhalation of nano-titanium dioxide particles [39, 52]. We have previously postulated that diminished fetal development after maternal nanoparticle exposure in our studies may be associated with indirect vascular deficiencies leading to uteroplacental ischemia in late-stages of pregnancy $[39,53,54]$. These vascular deficiencies are also evident after a single pulmonary exposure to nanotitanium dioxide particles during pregnancy $[53,54]$. We have also observed decreased fluid flow during ex vivo placental perfusion after gold nanoparticle infusion [24]. Interestingly, we identified reductions in fetal weight, placental weight, and increased number of fetal reabsorptions after an acute maternal nanoplastic pulmonary exposure in this study, but did not observe a reduction in fluid flow to the fetal compartment after direct infusion of nanopolystyrene particles into the uterine artery. Unfortunately, despite more recent studies, these limited data do not provide enough evidence to make definitive statements regarding adverse gestational or litter effects after maternal pulmonary nanomaterial exposure [50]. Therefore, future studies of uteroplacental function are necessary to clarify if the discrepancies in these results are based on differences between single, acute, or chronic nanopolystyrene exposures or if these changes are mediated only by metallic nanomaterials.

\section{Conclusion}

Collectively, these results identified the impact of a pulmonary exposure to an environmentally relevant dose of nanopolystyrene and examined maternal and fetal parameters and the translocation of plastic particles to, 
and deposition within fetal tissues. These data are vital to the understanding of plastic particulate toxicology and the developmental onset of health and disease. Future studies are required to provide a more detailed exploration of organ-specific toxicity and the implications of nanoplastic exposure on reproductive potential and fetal development.

\section{Acknowledgements}

We would like to recognize Ms. Chelsea M. Cary for her critical review of the manuscript and Cytoviva, Inc. for their assistance in acquiring the images for Fig. 3.

\section{Authors' contributions}

SF conducted the animal exposures, dissections, and was a major contributor in data analysis and writing the manuscript. JD conducted the animal exposures, placental perfusion experiments, and was a major contributor in data analysis and writing the manuscript. DS conducted the optical imaging studies and was a major contributor in data analysis. SK completed the nanoparticle characterizations. MG completed the histological reviews. LF completed the nanoparticle characterizations. EY contributed to data analysis of the optical imaging studies. PS developed the experimental design, oversaw the exposures and experiments, and was a major contributor to the data analysis and writing the manuscript. All authors read and approved the final manuscript.

\section{Funding}

This work was supported by the National Institute of Environmental Health Sciences (R00-ES024783), Rutgers Center for Environmental Exposures and Disease (P30-ES005022), and Rutgers Joint Graduate Program in Toxicology (T32-ES007148).

\section{Availability of data and materials}

All data generated or analyzed during this study are included in this published article.

\section{Ethics approval and consent to participate}

All animal experiments were approved by the Institutional Animal Care and Use Committee of Rutgers University.

\section{Consent for publication}

Not Applicable.

\section{Competing interests}

The authors declare that they have no competing interests.

\section{Author details}

${ }^{1}$ Environmental and Occupational Health Sciences Institute, Rutgers University, 170 Frelinghuysen Rd, Piscataway, NJ 08854, USA. ²Department of Pharmacology and Toxicology, Ernest Mario School of Pharmacy, Rutgers University, 160 Frelinghuysen Rd, Piscataway, NJ 08854, USA. ${ }^{3}$ Molecular Imaging Center, Rutgers University, 41 Gordon Rd, Piscataway, NJ 08854, USA. ${ }^{4}$ Department of Material Science and Engineering, School of Engineering, Rutgers University, 607 Taylor Rd, Piscataway, NJ 08854, USA. ${ }^{5}$ Research Pathology Services, Rutgers University, Piscataway, NJ 08854, USA.

\section{Received: 2 July 2020 Accepted: 15 October 2020}

Published online: 24 October 2020

\section{References}

1. Geyer R, Jambeck JR, Law KL. Production, use, and fate of all plastics ever made. Sci Adv. 2017;3(7):e1700782. https://doi.org/10.1126/sciadv.1700782.

2. Wagner $M$, Engwall M, Hollert $\mathrm{H}$. Editorial: (Micro) Plastics and the environment. Environ Sci Eur. 2014;26(1):16. https://doi.org/10.1186/s12302014-0016-3 https://www.ncbi.nlm.nih.gov/pubmed/27752414.

3. Prata JC. Airborne microplastics: consequences to human health? Environ Pollut. 2018;234:115-26. https://doi.org/10.1016/j.envpol.2017.11.043.

4. Allen $S$, Allen D, Phoenix VR, Le Roux G, Durántez Jiménez P, Simonneau A, et al. Atmospheric transport and deposition of microplastics in a remote mountain catchment. Nat Geosci. 2019;12(5):339-44. https://doi.org/10. 1038/s41561-019-0335-5 https://doi.org/10.1038/s41561-019-0335-5.

5. Stapleton PA. Toxicological considerations of nano-sized plastics. AIMS Environ Sci. 2019;6(5):367-78. https://doi.org/10.3934/environsci.2019.5.367.

6. Labor USDo: Regulations (Standards - 29 CFR). https://www.osha.gov/lawsregs/regulations/standardnumber/1910 (2017)

7. Wagner S, Reemtsma T. Things we know and don't know about nanoplastic in the environment. Nat Nanotechnol. 2019;14(4):300-1. https://doi.org/10. 1038/s41565-019-0424-z

8. Cox KD, Covernton GA, Davies HL, Dower JF, Juanes F, Dudas SE. Human consumption of microplastics. Environ Sci Technol. 2019;53(12):7068-74. https://doi.org/10.1021/acs.est.9b01517.

9. Stapleton PA, Minarchick VC, McCawley M, Knuckles TL, Nurkiewicz TR. Xenobiotic particle exposure and microvascular endpoints: a call to arms. Microcirculation. 2012;19(2):126-42 http://www.ncbi.nlm.nih.gov/ pubmed/21951337.

10. Campagnolo L, Massimiani M, Vecchione L, Piccirilli D, Toschi N, Magrini A, et al. Silver nanoparticles inhaled during pregnancy reach and affect the placenta and the foetus. Nanotoxicology. 2017;11(5):687-98. https://doi.org/ 10.1080/17435390.2017.1343875 https://www.ncbi.n/m.nih.gov/pubmed/2 8618895.

11. Stapleton PA, Minarchick VC, Cumpston AM, McKinney W, Chen BT, Sager TM, et al. Impairment of coronary arteriolar endothelium-dependent dilation after multi-walled carbon nanotube inhalation: a time-course study. Int J Mol Sci. 2012;13(11):13781-803. https://doi.org/10.3390/ijms131113781 http://www.ncbi.nlm.nih.gov/pubmed/23203034.

12. Miller MR, Raftis JB, Langrish JP, McLean SG, Samutrtai $P$, Connell SP, et al. Inhaled nanoparticles accumulate at sites of vascular disease. ACS Nano. 2017;11(5):4542-52. https://doi.org/10.1021/acsnano.6b08551.

13. Gate L, Disdier C, Cosnier F, Gagnaire F, Devoy J, Saba W, et al. Biopersistence and translocation to extrapulmonary organs of titanium dioxide nanoparticles after subacute inhalation exposure to aerosol in adult and elderly rats. Toxicol Lett. 2017;265:61-9. https://doi.org/10.1016/j.toxlet. 2016.11.009 https://www.ncbi.nlm.nih.gov/pubmed/27865850.

14. Avio CG, Gorbi S, Milan M, Benedetti M, Fattorini D, d'Errico G, et al. Pollutants bioavailability and toxicological risk from microplastics to marine mussels. Environ Pollut. 2015;198:211-22. https://doi.org/10.1016/j.envpol. 2014.12.021 https://www.ncbi.nlm.nih.gov/pubmed/25637744.

15. Toussaint B, Raffael B, Angers-Loustau A, Gilliland D, Kestens V, Petrillo M, et al. Review of micro- and nanoplastic contamination in the food chain. Food Add Contam Part A Chem Anal Control Exp Risk Assess. 2019;36(5): 639-73. https://doi.org/10.1080/19440049.2019.1583381.

16. Browne MA, Dissanayake A, Galloway TS, Lowe DM, Thompson RC. Ingested microscopic plastic translocates to the circulatory system of the mussel, Mytilus edulis (L). Environ Sci Technol. 2008;42(13):5026-31. https://doi.org/ 10.1021/es800249a https://www.ncbi.nlm.nih.gov/pubmed/18678044.

17. Mattsson K, Ekvall MT, Hansson LA, Linse S, Malmendal A, Cedervall T. Altered behavior, physiology, and metabolism in fish exposed to polystyrene nanoparticles. Environ Sci Technol. 2015;49(1):553-61. https://doi.org/10.1021/es5053655 https://www.ncbi.nlm.nih.gov/ pubmed/25380515.

18. Pitt JA, Trevisan R, Massarsky A, Kozal JS, Levin ED, Di Giulio RT. Maternal transfer of nanoplastics to offspring in zebrafish (Danio rerio): a case study with nanopolystyrene. Sci Total Environ. 2018;643:324-34. https://doi.org/10.1016/j. scitotenv.2018.06.186 https://www.ncbi.n/m.nih.gov/pubmed/29940444.

19. Xu M, Halimu G, Zhang Q, Song Y, Fu X, Li Y, et al. Internalization and toxicity: a preliminary study of effects of nanoplastic particles on human lung epithelial cell. Sci Total Environ. 2019;694:133794. https:// doi.org/10.1016/j.scitotenv.2019.133794 https://www.ncbi.nlm.nih.gov/ pubmed/31756791.

20. Wick P, Malek A, Manser P, Meili D, Maeder-Althaus X, Diener L, et al. Barrier capacity of human placenta for nanosized materials. Environ Health Perspect. 2010;118(3):432-6. https://doi.org/10.1289/ehp.0901200 https:// www.ncbi.nlm.nih.gov/pubmed/20064770.

21. Grafmueller S, Manser P, Diener L, Diener PA, Maeder-Althaus X, Maurizi L, et al. Bidirectional transfer study of polystyrene nanoparticles across the placental barrier in an ex vivo human placental perfusion model. Environ Health Perspect. 2015;123(12):1280-6. https://doi.org/10.1289/ehp.1409271 https://www.ncbi.nlm.nih.gov/pubmed/25956008.

22. Minarchick VC, Stapleton PA, Porter DW, Wolfarth MG, Ciftyurek E, Barger M, et al. Pulmonary cerium dioxide nanoparticle exposure differentially impairs 
coronary and mesenteric arteriolar reactivity. Cardiovasc Toxicol. 2013. http://www.ncbi.nlm.nih.gov/pubmed/23645470.

23. Minarchick VC, Stapleton PA, Sabolsky EM, Nurkiewicz TR. Cerium dioxide nanoparticle exposure improves microvascular dysfunction and reduces oxidative stress in spontaneously hypertensive rats. Front Physiol. 2015;6:339. https:/doi. org/10.3389/fphys.2015.00339 https://www.ncbi.nlm.nih.gov/pubmed/26635625.

24. D'Errico JN, Doherty C, Fournier SB, Renkel N, Kallontzi S, Goedken M, et al. Identification and quantification of gold engineered nanomaterials and impaired fluid transfer across the rat placenta via ex vivo perfusion. Biomed Pharmacother. 2019;117:109148. https://doi.org/10.1016/j.biopha.2019. 109148 https://www.ncbi.nlm.nih.gov/pubmed/31347503.

25. D'Errico JN, Fournier SB, Stapleton PA. Ex vivo perfusion of the rodent placenta. J Vis Exp. 2019;147:e59412. https://doi.org/10.3791/59412.

26. LoMauro A, Aliverti A. Respiratory physiology of pregnancy: physiology masterclass. Breathe (Sheff). 2015:11(4):297-301. https://doi.org/10.1183/ 20734735.008615 https://www.ncbi.nlm.nih.gov/pubmed/27066123.

27. Ji JY, J. Estimation of human equivalent exposure from rat inhalation toxicity study of silver nanoparticles using multi-path particle dosimetry model. Toxicol Res. 2012;1:206-10. https://doi.org/10.1039/c2tx20029e.

28. Tee JK, Yip LX, Tan ES, Santitewagun S, Prasath A, Ke PC, et al. Nanoparticles' interactions with vasculature in diseases. Chem Soc Rev. 2019:48(21):5381407. https://doi.org/10.1039/c9cs00309f.

29. Setyawati MI, Tay CY, Bay BH, Leong DT. Gold nanoparticles induced endothelial leakiness depends on particle size and endothelial cell origin. ACS Nano. 2017;11(5):5020-30. https://doi.org/10.1021/acsnano.7b01744.

30. Tay CY, Setyawati MI, Leong DT. Nanoparticle density: a critical biophysical regulator of endothelial permeability. ACS Nano. 2017;11(3):2764-72. https:// doi.org/10.1021/acsnano.6b07806.

31. Saunders NR, Liddelow SA, Dziegielewska KM. Barrier mechanisms in the developing brain. Front Pharmacol. 2012;3:46. https://doi.org/10.3389/fphar. 2012.00046

32. Engelhardt B. Development of the blood-brain barrier. Cell Tissue Res. 2003; 314(1):119-29. https://doi.org/10.1007/s00441-003-0751-z.

33. Kunovac A, Hathaway QA, Pinti MV, Goldsmith WT, Durr AJ, Fink GK, et al. ROS promote epigenetic remodeling and cardiac dysfunction in offspring following maternal engineered nanomaterial (ENM) exposure. Part Fibre Toxicol. 2019;16(1):24. https://doi.org/10.1186/s12989-019-0310-8 https:// www.ncbi.nlm.nih.gov/pubmed/31215478.

34. Hathaway QA, Durr AJ, Shepherd DL, Pinti MV, Brandebura AN, Nichols CE, et al. miRNA-378a as a key regulator of cardiovascular health following engineered nanomaterial inhalation exposure. Nanotoxicology. 2019;13(5): 644-63. https://doi.org/10.1080/17435390.2019.1570372 https://www.ncbi. nlm.nih.gov/pubmed/30704319.

35. Nichols CE, Shepherd DL, Hathaway QA, Durr AJ, Thapa D, Abukabda A, et al. Reactive oxygen species damage drives cardiac and mitochondrial dysfunction following acute nano-titanium dioxide inhalation exposure. Nanotoxicology. 2018;12(1):32-48. https://doi.org/10.1080/17435390.2017. 1416202 https://www.ncbi.nlm.nih.gov/pubmed/29243970.

36. Stapleton PA, Hathaway QA, Nichols CE, Abukabda AB, Pinti MV, Shepherd $\mathrm{DL}$, et al. Maternal engineered nanomaterial inhalation during gestation alters the fetal transcriptome. Part Fibre Toxicol. 2018;15(1):3. https://doi.org/ 10.1186/s12989-017-0239-8 http://www.ncbi.nlm.nih.gov/pubmed/29321036.

37. Hathaway QA, Nichols CE, Shepherd DL, Stapleton PA, McLaughlin SL, Stricker JC, et al. Maternal-engineered nanomaterial exposure disrupts progeny cardiac function and bioenergetics. Am J Physiol Heart Circ Physiol. 2017;312(3):H446-H58. https://doi.org/10.1152/ajpheart.00634.2016 https:// www.ncbi.nlm.nih.gov/pubmed/28011589.

38. Stapleton PA, Nichols CE, Yi J, McBride CR, Minarchick VC, Shepherd DL, et al. Microvascular and mitochondrial dysfunction in the female F1 generation after gestational $\mathrm{TiO} 2$ nanoparticle exposure. Nanotoxicology. 2015;9(8):941-51 http://www.ncbi.n/m.nih.gov/pubmed/25475392.

39. Stapleton PA, Minarchick VC, Yi J, Engels K, McBride CR, Nurkiewicz TR. Maternal engineered nanomaterial exposure and fetal microvascular function: does the Barker hypothesis apply? Am J Obstet Gynecol. 2013; 209(3):227 e1-11. https://doi.org/10.1016/j.ajog.2013.04.036 http://www.ncbi. nlm.nih.gov/pubmed/23643573.

40. Hougaard KS, Jackson P, Kyjovska ZO, Birkedal RK, De Temmerman PJ, Brunelli $A$, et al. Effects of lung exposure to carbon nanotubes on female fertility and pregnancy. A study in mice. Reprod Toxicol. 2013;41:86-97. https://doi.org/10.1016/j.reprotox.2013.05.006 https://www.ncbi.nlm.nih.gov/ pubmed/23714338.
41. Kyjovska ZO, Boisen AM, Jackson P, Wallin H, Vogel U, Hougaard KS. Daily sperm production: application in studies of prenatal exposure to nanoparticles in mice. Reprod Toxicol. 2013;36:88-97. https://doi.org/10.1016/j.reprotox.2012. 12.005 https://www.ncbi.nlm.nih.gov/pubmed/23295323.

42. Jackson P, Hougaard KS, Vogel U, Wu D, Casavant L, Williams A, et al. Exposure of pregnant mice to carbon black by intratracheal instillation: toxicogenomic effects in dams and offspring. Mutat Res. 2012;745(1-2):7383 http://www.ncbi.nlm.nih.gov/pubmed/22001195.

43. Umezawa M, Onoda A, Korshunova I, Jensen ACO, Koponen IK, Jensen KA et al. Maternal inhalation of carbon black nanoparticles induces neurodevelopmental changes in mouse offspring. Part Fibre Toxicol. 2018; 15(1):36. https://doi.org/10.1186/s12989-018-0272-2 https://www.ncbi.nlm. nih.gov/pubmed/30201004.

44. Engler-Chiurazzi EB, Stapleton PA, Stalnaker JJ, Ren X, Hu H, Nurkiewicz TR, et al. Impacts of prenatal nanomaterial exposure on male adult SpragueDawley rat behavior and cognition. J Toxicol Environ Health A. 2016;79(11): 447-52. https://doi.org/10.1080/15287394.2016.1164101 https://www.ncbi. nlm.nih.gov/pubmed/27092594.

45. Hong F, Zhou Y, Ji J, Zhuang J, Sheng L, Wang L. Nano-TiO2 inhibits development of the central nervous system and its mechanism in offspring mice. J Agric Food Chem. 2018;66(44):11767-74. https://doi.org/10.1021/acs. jafc.8b02952 https://www.ncbi.nlm.nih.gov/pubmed/30269504.

46. Fadare OO, Wan B, Liu K, Yang Y, Zhao L, Guo LH. Eco-Corona vs protein Corona: effects of humic substances on Corona formation and Nanoplastic particle toxicity in daphnia magna. Environ Sci Technol. 2020;54(13):8001-9. https://doi.org/10.1021/acs.est.0c00615 https://www.ncbi.nlm.nih.gov/ pubmed/32464058.

47. Soto AM, Justicia H, Wray JW, Sonnenschein C. p-Nonyl-phenol: an estrogenic xenobiotic released from "modified" polystyrene. Environ Health Perspect. 1991;92:167-73. https://doi.org/10.1289/ehp.9192167.

48. Kik K, Bukowska B, Sicinska P. Polystyrene nanoparticles: sources, occurrence in the environment, distribution in tissues, accumulation and toxicity to various organisms. Environ Pollut. 2020;262:114297. https://doi.org/10.1016/j. envpol.2020.114297 https://www.ncbi.nlm.nih.gov/pubmed/32155552.

49. Withey JR. Quantitative analysis of styrene monomer in polystyrene and foods including some preliminary studies of the uptake and pharmacodynamics of the monomer in rats. Environ Health Perspect. 1976; 17:125-33. https://doi.org/10.1289/ehp.7617125.

50. Hougaard KS, Campagnolo L, Chavatte-Palmer P, Tarrade A, Rousseau-Ralliard D, Valentino $S$, et al. A perspective on the developmental toxicity of inhaled nanoparticles. Reprod Toxicol. 2015;56:118-40. https://doi.org/10.1016/j. reprotox.2015.05.015 https://www.ncbi.nlm.nih.gov/pubmed/26050605.

51. Grafmueller S, Manser P, Diener L, Maurizi L, Diener PA, Hofmann H, et al. Transfer studies of polystyrene nanoparticles in the ex vivo human placenta perfusion model: key sources of artifacts. Sci Technol Adv Mater. 2015;16(4): 044602. https://doi.org/10.1088/1468-6996/16/4/044602 https://www.ncbi. nlm.nih.gov/pubmed/27877820.

52. Bowdridge EC, Abukabda AB, Engles KJ, McBride CR, Batchelor TP, Goldsmith WT, et al. Maternal engineered nanomaterial inhalation during gestation disrupts vascular Kisspeptin reactivity. Toxicol Sci. 2019;169(2):52433. https://doi.org/10.1093/toxsci/kfz064 https://www.ncbi.nlm.nih.gov/ pubmed/30843041.

53. Fournier SB, Kallontzi S, Fabris L, Love C, Stapleton PA. Effect of gestational age on maternofetal vascular function following single maternal engineered nanoparticle exposure. Cardiovasc Toxicol. 2019. https://doi.org/10.1007/ s12012-019-09505-0 https://www.ncbi.nlm.nih.gov/pubmed/30734150.

54. Stapleton PA, McBride CR, Yi J, Abukabda AB, Nurkiewicz TR. Estrous cycledependent modulation of in vivo microvascular dysfunction after nanomaterial inhalation. Reprod Toxicol. 2018;78:20-8. https://doi.org/10.1016/j.reprotox 2018.03.001 https://www.ncbi.nlm.nih.gov/pubmed/29545171.

\section{Publisher's Note}

Springer Nature remains neutral with regard to jurisdictional claims in published maps and institutional affiliations. 